\title{
Role of Testosterone in Swimming Exercise-induced Analgesia in Rats
}

\author{
Dheeraj Kumar Sharma ${ }^{1, *}$, Niraj Kumar Singh², Ahsas Goyal², Jeetendra Kumar Gupta², \\ Harlokesh Narayan Yadav ${ }^{3}$
}

1SGT College of Pharmacy, SGT University, Gurugram, Haryana, INDIA.

${ }^{2}$ Institute of Pharmaceutical Research, GLA University, Mathura, Uttar Pradesh, INDIA.

${ }^{3}$ All India Institute of Medical Sciences, Gautam Nagar, Ansari Nagar East, New Delhi, INDIA.

\begin{abstract}
Objective: "Feel good effect" of exercise is well known. Activation of pain inhibitory mechanisms after exercise is also well documented. Swimming is considered as a beneficial exercise as well as health-promoting sport. The significance of testosterone in swimming exercise-induced analgesia is yet to be understood. Therefore, it is worthwhile to investigate the significance of testosterone in swimming exercise-induced analgesia. Materials and Methods: The basal tail flick latencies of all animals were recorded by using tail flick analgesiometer. In order to observe the effect of testosterone on swimming exercise-induced analgesia, testicles of animals of some groups were surgically removed. Then animals were subjected to swimming sessions of different patterns. After swimming, tail flick latencies were measured. Results: Swimming sessions resulted in increase in pain thresholds of all animals. Castration negatively affected the degree of analgesia achieved in rats. However, daily treatment of testosterone propionate $(500 \mu \mathrm{g} / \mathrm{kg}$, s.c.) improved swim-induced analgesia in castrated rats. Moreover, daily administration of naloxone hydrochloride $(1 \mathrm{mg} / \mathrm{kg}$, i.p.) fifteen min prior to swimming suppressed testosterone therapy resulted in an increase in swim-induced analgesia in castrated animals. Conclusion: We concluded that testosterone plays a significant role in swimming exercise-induced analgesia in male Wistar albino rats and this positive effect of testosterone on pain threshold might be mediated through its probable effect on the endogenous opioid system.
\end{abstract}

Key words: Castration, Swimming exercise, Pain threshold, Testosterone, Endogenous opioids.

\section{INTRODUCTION}

Pain is a problematic issue worldwide. ${ }^{1}$ It is one of the most common reasons for which patients require medical care. ${ }^{2}$ Pain is defined as "an unpleasant sensory and emotional experience associated with actual or potential tissue damage, or described in terms of such damage". 3 Sometimes surprisingly, troopers or warriors wounded in battlefield report that they do not experience lousy pain during the war. ${ }^{4}$ Some of the habitual runners experience acute states of euphoria during or after running exercise. ${ }^{5}$ Research studies on animals indicate multiple endogenous analgesia systems. ${ }^{6}$ Various endogenous opioid peptides and endocannabinoids are well reported to have analgesic properties. ${ }^{7,8}$ A planned, repetitive physical activity in order to maintain and/or improve physical fitness is said to be exercised. ${ }^{9}$ Exercise significantly increases serum $\beta$-endorphin levels as compared to its resting values. ${ }^{10}$ Exercise elevates the pain threshold by triggering the release of endogenous opioids, which activate nociceptive inhibitory mechanisms. ${ }^{11}$ It is a well-known fact that swimming is a good exercise. Swimming exercise significantly minimized the number of acetic acid-induced pain responses in mice when compared with the nonexercised group. ${ }^{12}$ It has been previously
Submission Date: 27-02-2019; Revision Date: 17-05-2019; Accepted Date: 26-07-2019

DOI: 10.5530/ijper.53.4.130 Correspondence: Mr. Dheeraj Kumar Sharma,

SGT College of Pharmacy, SGT University, Gurugram-122505, Haryana, INDIA.

Phone: +919457057966

E-mail: sharmadk33@gmail. com

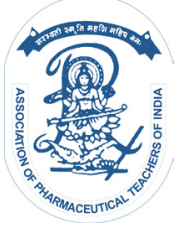

www.ijper.org 
reported that naloxone significantly attenuates swim-induced anti-nociceptive effects in adult rats. ${ }^{13}$ Testosterone is a primary male sex hormone mainly secreted by testes. ${ }^{14}$ It has been found that testosterone intensifies analgesia, cognitive performance and decreases anxiety in rats. ${ }^{15}$ Low dose transdermal testosterone therapy is reported to increase angina threshold in human subjects. ${ }^{16}$ At an identical level of pain intensity, a higher degree of $\mu$-opioid system activation has been observed in anterior thalamus, ventral basal ganglia and amygdala of men than in women. ${ }^{17}$ It has been documented that testosterone may increase the sensitivity of adult male rats to $\mu$ and $\mathrm{k}$ opioid anti-nociception. ${ }^{18}$ In a study, testosterone deficient men were found more likely to suffer from irritability, anxiety, insomnia, poor memory, low libido and reduced muscle and bone mass. ${ }^{19}$

In this study, we explored the effect of castration on swim-induced analgesia in male Wistar rats. We also investigated whether the role of testosterone therapy in restoring swim-induced analgesia in castrated rats is mediated through the endogenous opioid system.

\section{MATERIALS AND METHODS}

\section{Animals}

Adult male Wistar albino rats having an average body weight of $225 \mathrm{~g} \pm 10 \%$ were housed in a controlled temperature of $22 \pm 2^{\circ} \mathrm{C}$ with $12: 12 \mathrm{~h}$ light-dark schedule. All animals were fed on standard chow diet (wheat flour $22.5 \%$, roasted Bengal gram powder $60 \%$, skimmed milk powder $5 \%$, casein $4 \%$, refined oil $4 \%$, salt mixture with starch $4 \%$ and vitamin and choline mixture $0.5 \%$ ) and provided water ad libitum. All the experimental procedures were performed in accordance with the approval of the Institutional Animal Ethical Committee (1260/PO/Ere/S/09/CPCSEA/IAEC/2015/P.Col./ R4) under strict compliance of Committee for the Purpose of Control and Supervision of Experiments on Animals (CPCSEA) guidelines. Further, the experiments were conducted in accordance with the principles of laboratory animal care (National Research Council US Committee for the Update of Guide for the Care and Use of Laboratory Animals).

\section{Drugs and chemicals}

Testosterone Propionate (TP), an ester of testosterone was obtained from Sigma Aldrich Chemical Co. Testosterone propionate $500 \mu \mathrm{g} / \mathrm{kg}$ was dissolved in olive oil for subcutaneous (s.c.) administration. ${ }^{20}$ Naloxone hydrochloride (Naloxone), an opioid antagonist was obtained from Sigma Aldrich Chemicals Co. Naloxone $1 \mathrm{mg} / \mathrm{kg}$ was dissolved in normal saline $(0.9 \%$ sodium chloride solution) for intraperitoneal (i.p.) administration ${ }^{21}$ All drugs and chemicals used in the experimental study were of analytical grade and freshly prepared before use.

\section{Surgical castration}

Animals were anesthetized by thiopental sodium $40 \mathrm{mg} / \mathrm{kg}$, i.p. ${ }^{22}$ The surgical castration was performed as discussed by Delev et al. ${ }^{23}$ The skin was shaved prior to surgery. A $10 \mathrm{~mm}$ long incision was made on scrotal skin apically. The incision was extended to a few $\mathrm{mm}$ of right and left sacs. Testes were pulled out gently. Vas deferens and blood vessels were ligated with silk thread. Both testicles were removed. The remaining tissue was carefully placed back in to the abdominal cavity. The incision was then closed using silk thread. The incisions were treated with topical neomycin sulfate powder (Nebasulf topical powder, Pfizer) for preventing microbial infection. For the purpose of healing, castrated rats were placed in individual cages with a free approach to food and water. Castrated rats were taken into the study after 6 weeks of castration providing time for the depletion of endogenous testosterone. ${ }^{24}$

\section{Experimental protocol}

The animals were randomly assigned to eleven groups containing six rats $(n=6)$ per group. Animals were individually allowed to swim in water filled up to half of an open circular pool of diameter $160 \mathrm{~cm}$ and depth $61 \mathrm{~cm}$. During swimming, the temperature of the water was maintained at $25^{\circ} \mathrm{C}$ to induce analgesia in rats. ${ }^{25}$ After swimming, animals were dried gently by using a soft cloth.

Group I: Normal control $(n=6)$ : Intact animals were not subjected to swimming exercise. Tail flick latencies were measured on a weekly interval for the assessment of pain threshold.

Group II: Normal intact animals allowed to swim for $15 \mathrm{~min}$ for a single day only $(n=6)$ : Intact animals were allowed to swim for $15 \mathrm{~min}$ for a single day only; tail-flick latencies were measured on the same day and then on a weekly interval.

Group III: Castrated rats allowed to swim for 15 min for a single day only $(n=6)$ : Castrated rats were allowed to swim for 15 min for a single day only; tailflick latencies were measured on the same day and then on a weekly interval.

Group IV: Normal intact animals allowed to swim every day for gradually increasing time period $(\mathbf{n}=6)$ : Intact rats were allowed to swim in a manner given in Table 1 and tail flick latencies were measured on a weekly interval. 
Table 1: Swimming protocol for group IV.

\begin{tabular}{|c|c|c|}
\hline S.NO. & $\begin{array}{c}\text { Duration of swimming } \\
\text { ( } \mathbf{m i n})\end{array}$ & Days \\
\hline 1. & $3 \mathrm{~min}$ & (from Day 1 to Day 4) \\
\hline 2. & $6 \mathrm{~min}$ & (from Day 5 to Day 8) \\
\hline 3. & $9 \mathrm{~min}$ & (from Day 9 to Day 12) \\
\hline 4. & $12 \mathrm{~min}$ & (from Day 13 to Day16) \\
\hline 5. & $15 \mathrm{~min}$ & (from Day 17 to Day 20) \\
\hline 6. & $15 \mathrm{~min}$ & (Day 20 onwards) \\
\hline
\end{tabular}

Table 2: Swimming protocol for group V.

\begin{tabular}{|c|c|c|}
\hline S.NO. & $\begin{array}{c}\text { Duration of swimming } \\
\text { (min) }\end{array}$ & Days \\
\hline 1. & $3 \mathrm{~min}$ & (from Day 1 to Day 4) \\
\hline 2. & $6 \mathrm{~min}$ & (from Day 5 to Day 8 ) \\
\hline 3. & $9 \mathrm{~min}$ & (from Day 9 to Day 12) \\
\hline 4. & $12 \mathrm{~min}$ & (from Day 13 to Day16) \\
\hline 5. & $15 \mathrm{~min}$ & (from Day 17 to Day 20) \\
\hline 6. & $15 \mathrm{~min}$ per day & (Day 20 onwards) \\
\hline
\end{tabular}

Group V: Castrated animals allowed to swim every day for gradually increasing time period $(n=6)$ : Castrated rats were allowed to swim in a manner given in Table 2 and tail flick latencies were measured on a weekly interval.

Group VI: Normal intact animals allowed to swim 15 min every day $(n=6)$ : Rats were allowed to swim daily for $15 \mathrm{~min}$ and pain thresholds were measured on a weekly interval.

Group VII: Castrated animals exposed to daily swimming for $15 \mathrm{~min}(n=6)$ : Castrated rats were allowed to swim daily for 15 min per day and tail flick latencies were measured weekly.

Group VIII: Vehicle (olive oil) treated castrated animals allowed to swim daily for $15 \mathrm{~min}(n=6)$ : Castrated rats were daily given olive oil $(1 \mathrm{ml} / \mathrm{kg}$, s.c.) and allowed to swim every day for $15 \mathrm{~min}$. Pain thresholds were measured weekly.

Group IX: Testosterone propionate treated castrated animals allowed to swim for $15 \mathrm{~min}$ per day $(\mathbf{n}=\mathbf{6})$ Castrated rats were daily administered testosterone propionate $500 \mu \mathrm{g} / \mathrm{kg}$, s.c. ${ }^{20,26}$ and allowed to swim daily for $15 \mathrm{~min}$. Pain thresholds were measured weekly.

Group X: Castrated animals treated with normal saline and olive oil were allowed to swim every day for $15 \mathrm{~min}(n=6)$ : Castrated rats treated daily with normal saline $1 \mathrm{ml} / \mathrm{kg}$, i.p. and olive oil $1 \mathrm{ml} / \mathrm{kg}$, s.c. were allowed to swim for $15 \mathrm{~min}$ per day. Pain thresholds were measured weekly.
Group XI: Castrated animals treated with naloxone hydrochloride and testosterone propionate were exposed to swimming for 15 min per day $(n=6)$ Castrated rats were daily administered with naloxone hydrochloride ( $1 \mathrm{mg} / \mathrm{kg}$, i.p.) and testosterone propionate $(500 \mu \mathrm{g} / \mathrm{kg}$, s.c.) and allowed to swim daily for $15 \mathrm{~min}$. Naloxone was daily administered 15 min before swimming sessions. Pain thresholds were measured weekly.

\section{Assessment of pain threshold by measuring tail flick latencies}

Tail flick latencies of the animals were considered as their pain threshold. ${ }^{27}$ Pain threshold was measured by tail flick analgesiometer (Rolex, India). Animals showing basal tail flick latencies below $3 \mathrm{sec}$ and above $5 \mathrm{sec}$ were excluded from the experimental protocol. Current passing through naked nichrome wire was set at 3 ampere ${ }^{28}$ to make the wire hot. A distance of about $1.5 \mathrm{~cm}$ was maintained between the heat source and tail skin to avoid tissue damage. About 1-2 $\mathrm{cm}$ portion of the tail tip was exposed to the heat source. ${ }^{29}$ To avoid tissue damage, cut-off time was fixed as $10 \mathrm{sec}$. The time between placing the tail on exposure to heat and flick/withdrawal of tail was noted as tail flick latency. Tail flick latencies were measured at weekly interval.

\section{Statistical analysis}

The results are presented as mean \pm SD (Standard Deviation). The data were analyzed using a two-way Analysis of Variance (ANOVA). The $p$-value $<0.05$ was considered statistically significant.

\section{RESULTS}

Although in intact and castrated male rats, swimming in water at $25^{\circ} \mathrm{C}$ has been found to raise pain thresholds. This increase in latencies of the tail flick in castrated rats was not as high as normal rats. The peak tail-flick latencies were observed between 15 and $30 \mathrm{~min}$ after swimming sessions as previously reported. ${ }^{25}$ This report presents data based on observed peak tail flick latencies.

\section{Effect of single day swimming session on pain threshold}

Intact male rats who had a one-day swimming session of 15 min withdrew their tails later than the control group (group II vs. group I). After a single day swimming session of 15 min compared to intact rats (group III vs. group II), tail flick latencies were significantly lower in castrated rats. When the pain threshold was measured one week after this day of swimming, it was found that the analgesic effect of swimming in both groups was abolished. In addition, in comparison with intact male 
rats (group III vs. group II), the pain thresholds of castrated male rats were significantly reduced. In addition, the measurement of tail flick latencies in the following weeks after the day of swimming revealed that the pain thresholds of castrated male rats were below their basic values, while intact animals withdrew their tails before swimming. (Figure 1A).

\section{Effect of swimming sessions of gradually increasing time durations on pain threshold}

At the first week, the pain threshold was found increased but only up to a little extent in both castrated and noncastrated normal rats. With the gradual increase in the duration of swimming, latency in tail withdrawal from radiant heat source was found to be increased proportionally. The maximum peak of the pain threshold was noted on the $4^{\text {th }}$ week. On exposure to swimming sessions of gradually increasing durations, elevation in tail flick latencies of castrated male rats was found to be significantly lesser than that observed in intact male rats (group V vs. group IV). Castrated male rats were observed to withdraw their tails significantly faster than intact rats (Figure 1B).

\section{Effects of daily swimming sessions of $15 \mathrm{~min}$ on pain threshold}

Normal male rats allowed to swim for 15 min daily were observed to show significantly higher post-swimming analgesic responses in comparison of castrated animals exposed to daily swimming for $15 \mathrm{~min}$ (group VI vs. group VII). Maximum tail-flick latencies were observed on week 4 measurement. A significant difference in swim-induced delay in tail flick responses was detected in both VI and VII groups as compared to normal group (Figure 1C).

\section{Effect of testosterone replacement therapy on pain thresholds}

Testosterone propionate administration to castrated animals significantly increased the pain threshold when compared to untreated castrated rats allowed to swim for 15 min (group IX vs. group VII). Tail flick latencies of testosterone propionate treated castrated animals exposed to daily swimming sessions of $15 \mathrm{~min}$ were found equivalent to intact swimming group. Vehicles treated castrated rats did not show any significant variation from vehicle untreated castrated male rats (Figure 1D).

\section{Effect of naloxone on pain thresholds of rats receiving testosterone propionate therapy}

Animals receiving both naloxone and testosterone propionate withdrew their tails significantly faster than animals receiving the testosterone propionate therapy alone (group XI vs. IX). In addition to this, it was observed that castrated animals receiving vehicle treatment exhibited the same degree of swim-induced increase in pain threshold as shown by castrated animals not getting any drug/vehicle treatment (Figure 1E).

\section{DISCUSSION}

In our study, we found that swimming in water at a temperature of $25^{\circ} \mathrm{C}$ induces analgesia in male Wistar rats, which is consistent with previous findings. ${ }^{25}$ During the study, we observed that all types of swimming protocols (single day swimming session, daily swimming with the gradual increase in duration and daily swimming of fixed duration i.e. $15 \mathrm{~min}$ ) resulted in the elevation of pain thresholds in male Wistar rats which support the previous reports regarding swim-induced antinociception in rodents. ${ }^{12} \mathrm{~A}$ comparatively lesser degree of swim-induced analgesia in castrated male rats indicates the importance of testosterone in intrinsic pain reducing mechanisms. As depicted in Figure 1A, we observed that tail flick latencies were elevated only on the day of swimming, while on weekly assessment of pain threshold after that single day swimming session of 15 min, elevated pain threshold was found to be reduced which indicated towards time limited activation of pain reducing mechanisms in the body. Animals subjected to gradually increasing daily swimming pattern (Figure 1B) were found to exhibit higher pain thresholds than animals exposed to a single day swimming (Figure 1A). The reason behind this progressive increase in pain threshold might be the up-regulation of $\mu$ opioid receptors in the Ventral Tegmental Area (VTA) male rat's brain. ${ }^{30}$ There is a high possibility of involvement of VTA in pain sensation as the intra-VTA infusion of morphine significantly reduced pain in male rats. ${ }^{31}$ Expectedly, rats exposed to swimming for 15 min per day since starting achieved highest pain threshold (Figure 1C) which supports the previous finding that swim session of 15 min produces more profound anti-nociception than a shorter session. ${ }^{32}$ For further exploration, we choose groups that were acquiesced to swimming for $15 \mathrm{~min}$ per day. Castration resulted in significantly lesser swim-induced analgesia when compared to intact animals although it was regained by testosterone propionate therapy (Figure 1D) which supports the previously documented findings that removal of testes (primary source of testosterone) has been observed to result in decreased pain threshold which was regained after testosterone supplementation, ${ }^{20}$ gonadectomized male rats treated with testosterone were found to have 


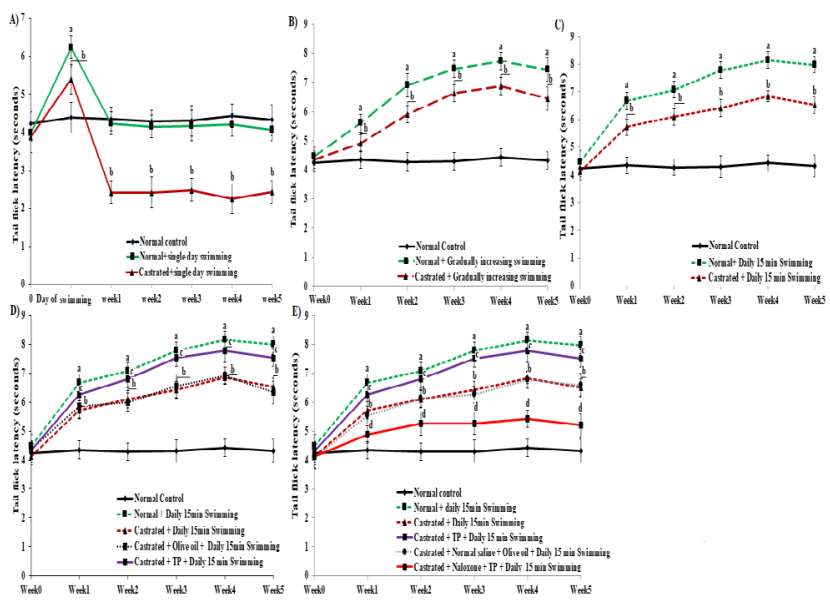

Figure 1: A) Effect of single day swimming session of 15 min duration on pain threshold. $a=p<0.05$ vs. normal control, $b=p<0.05$ vs. normal single day swimming; B) Effect of swimming sessions of gradually increasing time duration on pain threshold. $a=p<0.05$ vs. normal control, $b=p<0.05$ normal+ daily gradually increasing swimming; C) Effect of daily swimming sessions of $15 \mathrm{~min}$ duration on pain threshold. $a=p<0.05 \mathrm{vs}$ normal control, $p=p<0.05$ vs. normal daily 15 min swimming; D) Effect of testosterone replacement therapy on swimming exercise-induced analgesia in male castrated rats. $a=p<0.05$ vs. normal control, $b=p<0.05$ vs. normal daily 15 min swimming, $c=p<0.05$ vs. castrated + daily $15 \mathrm{~min}$ swimming and olive oil treated castrated rats + daily 15 min swimming; E) Effect of naloxone on testosterone replacement therapy resulted increase in swimming exercise-induced analgesia in male castrated rats. $a=p<0.05$ vs. normal control, $b=p<0.05$ vs. normal daily 15 min swimming, $c=p<0.05$ vs. castrated + daily $15 \mathrm{~min}$ swimming and normal saline, olive oil treated castrated rats + daily 15 min swimming, $d=p<0.05$ vs. castrated + testosterone + daily 15 min swimming. All values are expressed in mean \pm Standard Deviation (S.D.).

longer tail withdrawal latencies in comparison of gonadectomized rats not treated with testosterone. ${ }^{18}$ Our work revealed the significance of testosterone in swimming exercise-induced analgesia as the reduced analgesic effect of swimming exercise in castrated male rats was found to be restored with testosterone replacement therapy. When naloxone hydrochloride (a well-known opioid receptor antagonist) $1 \mathrm{mg} / \mathrm{kg}$ was daily administered intraperitoneally (15 min prior to swimming session) to castrated rats receiving testosterone propionate therapy, a significant reduction in swim-induced analgesia (Figure 1E) was observed when compared to castrated animals treated merely with testosterone and exposed to swimming session daily for $15 \mathrm{~min}$. This suppressing effect of naloxone indicated that the pain threshold enhancing the effect of testosterone in castrated male rats might be directly or indirectly mediated through endogenous opioid mechanisms. This contention is supported by some earlier documented reports such as testosterone treated castrated male rats were found to have significantly higher levels of Proopiomelanocortin (POMC; precursor of $\beta$ endorphins) mRNA signals in comparison of sham-treated castrated male rats and POMC mRNA signals in testosterone-treated castrated male rats were very similar to that of intact control rats, ${ }^{33}$ castration decreased and testosterone increased anti-nociception produced by opioid agonists in male rats. ${ }^{18}$

\section{CONCLUSION}

On the basis of the above discussion, it can be concluded that the regular swimming sessions might have proved to be beneficial in order to increase the pain threshold. In terms of increase in pain threshold, castrated male rats were found significantly less benefited by swimming sessions when compared to intact male rats. Treatment with testosterone propionate $500 \mu \mathrm{g} / \mathrm{kg} /$ day s.c. was proved to be significantly effective in order to improve swimming exercise-induced an increase in pain threshold in castrated male rats. It indicated that the adequate existence of testosterone is required for the normal functioning of pain reducing mechanisms in the body. In addition to this, we came to the conclusion that the positive influence of testosterone on pain threshold might be mediated through its probable effect on the endogenous opioid analgesic system. In a nutshell, the deficiency of testosterone might have a negative impact on regular swimming exercise-induced increase in pain threshold of an individual. Though, it can be compensated by testosterone therapy.

\section{ACKNOWLEDGEMENT}

Vocabulary falls short to express my thankfulness to Shri Narayan Das Agrawal Ji (Chancellor, GLA University, Mathura, UP, India), Prof. Pradeep Mishra (Director, Institute of Pharmaceutical Research, GLA University), Prof. Meenakshi Bajpai (HOD, Institute of Pharmaceutical Research, GLA University) and Dr. Harlokesh Narayan Yadav, Associate Professor, GLA University, Mathura (Tenure- 2012-2015) (Currently working in AIIMS, New Delhi) for their worthy inspiration and continuous support throughout the research work. All authors contributed equally to this work. H.N.Y. J.K.G and D.K.S (D.K.S.- M. Pharm Research Scholar at the time of this project in GLA University, Mathura, U.P. but now working as Assistant Professor in SGT University, Gurugram, Haryana) developed the concept and designed experiment. D.K.S performed experiment in the laboratory. A.G., N.K.S and H.N.Y. carried out the analysis of results. D.K.S. prepared the manuscript. 


\section{CONFLICT OF INTEREST}

The authors declare no conflict of interest.

\section{ABBREVIATIONS}

CPCSEA: Committee for the Purpose of Control and Supervision of Experiments on Animals; IAEC: Institutional Animal Ethics Committee; SD: Standard Deviation; TP: Testosterone Propionate; VTA: Ventral Tegmental Area; POMC: Proopiomelanocortin.

\section{REFERENCES}

1. Daniel SG, Summer JM. Pain as a global public health priority. BMC Public Health. 2011;11(1):770.

2. Radnovich CR, Chapman CR, Gudin JA, Panchal SJ, Webster LR, Perqolizzi JVJR. Acute pain: effective management requires comprehensive assessment. Postqrad Med. 2014;126(4):59-72.

3. Merskey H, Bogduk N. Classification of chronic pain: descriptions of chronic pain syndromes and definition of pain terms. IASP Press Seattle: Washington. 1994;210-3.

4. Beecher HK. Pain in men wounded in battle. Ann Surg. 1946;123(1):96-105.

5. Dishman RK. Medical psychology in exercise and sport. Med Clin North Am. 1985;69(1):123-43.

6. Koltyn KF. Analgesia following exercise: a review. Sports Med. 2000;29(2):85-9.

7. Guindon J, Hohmann AG. The endocannabinoid system and pain. CNS Neurol Disord Targets. 2009;8(6):403-21.

8. Koneru A, Satyanarayana S, Rizwan S. Endogenous opioids: the physiological role and receptors. Glob J Pharmacol. 2009;3(3):149-53.

9. Caspersen CJ, Powell KE, Christenson GM. Physical activity, exercise and physical fitness: definitions and distinctions for health-related research. Public Health Rep. 1985;100(2):126-31.

10. Goldfarb AH, Hatfield BD, Sforzo GA, Flynn MG. Serum beta-endorphin levels during a graded exercise test to exhaustion. Med Sci Sports Exerc. 1987;19(2):78-82.

11. Nijis J, Kosek E, Oosterwijck JV, Meeus M. Dysfunctional endogenous analgesia during exercise in patients with chronic pain: To exercise or not to exercise. Pain Physician. 2012;15(3S):205-13.

12. Martins LM, Martins DF, Rodrigo M, Santos UD, Speckhann B, Gadotti VM, et al. High-intensity extended swimming exercise reduces pain-related behaviour in mice: involvement of endogenous opioids and the serotonergic system. J Pain. 2010;11(12):1384-93.

13. Kitchen I, Pinker SR. Antagonism of swim-stress-induced antinociception by the -opioid receptor antagonist naltrindole in adult and young rats. Brit $\mathrm{J}$ Pharmacol. 1990;100(4):685-8.

14. Breedlove SM. Sexual dimorphism in the vertebrate nervous system. J Neurosci. 1992;12(11):4133-42.
15. Frye CA, Seliga AM. Testosterone increases analgesia, anxiolysis and cognitive performance of male rats. Cogn Affect Behav Neurosci. 2001;1(4):371-81.

16. English KM, Steeds RP, Jones TH, Diver MJ, Channer KS. Low-dose transdermal testosterone therapy improves angina threshold in men chronic stable angina. Circulation. 2000;102(16):1906-11.

17. Zubieta JK, Smith YR, Bueller JA, Xu Y, Kilbourn MR, Jewett DM, et al. $\mu$-opioid receptor-mediated antinociceptive response differ in men and women. J Neurosci. 2002;22(12):5100-7.

18. Stoffel EC, Ulibarri CM, Folk JE, Rice KC, Craft RM. Gonadal hormone modulation of mu, kappa and delta opioid antinociception in male and female rats. J Pain. 2005;6(4):261-74.

19. Sternbach $\mathrm{H}$. Age-associated testosterone decline in men: clinical issues for psychiatry. Am J Psychiatry. 1998;155(10):1310-8.

20. Pednekar JR, Mulgaonker VK. Role of testosterone on pain threshold in rats. Indian J Physiol Pharmacol. 1995;39(4):423-4.

21. Bastidas GNQ, Duran CC, Gonzalez HIR, Murbartian J, Soto VG. Analysis of the mechanisms underlying the antinociceptive effect of epicatechin in diabetic rats. Life Sciences. 2013;93(14):637-45.

22. Cherksey BD, Altszuler N. On the mechanism of potentiation by morphine of thiopental sleeping time. Pharmacology. 1974;12(6):362-71.

23. Delev DP, Davcheva DP, Kostadinov ID, Kostadinova II. Effect of testosterone propionate on erythropoiesis after experimental orchiectomy. Folia Medica. 2013;55(2):51-7.

24. Ward GR, Rahman AAA. Effect of testosterone replacement or duration of castration on baroreflex bradycardia in conscious rats. BMC Pharmacology. 2005;5(1):91-6.

25. Gutièrrez AC, Keller EA. Analgesic response to stress is reduced in perinatally undernourished rats. J Nutr. 1997;127(5):765-9.

26. Chauhan NS, Rao CV, Dixit VK. Effect of Curculigoorchioides rhizomes on sexual behaviour of male rats. Fitoterapia. 2007;78(7-8):530-4.

27. Lee JH, Cox DJ, Mook DG, McCarty RC. Effect of hyperglycemia on pain threshold in alloxan-diabetic rats. Pain. 1990;40(1):105-7.

28. Brahmbhatt MR, Patel JM, Patel VB, Saluja AK. Analgesic and antiinflammatory activity of leaves of Riveahypocrateriformis. J Pharmacog Phytother. 2010;2(1):1-3.

29. Kulkarni SK. Hand book of experimental pharmacology. Vallabh Prakashan: India. 2005;123-5.

30. Nikulina EM, Miczek KA, Hammer RPJ. Prolonged effects of repeated social defeat stress on mRNA expression and function of $\mu$-opioid receptors in the ventral tegmental area of rats. Neuropsychopharmacol. 2005;30(6):1096-103.

31. Altier N, Stewart J. Dopamine receptor antagonists in the nucleus accumbens attenuate analgesia induced by ventral tegmental area substance $\mathrm{P}$ or morphine and by nucleus accumbens amphetamine. J Pharmacol Exp Ther. 1998;285(1):208-15.

32. Parikh D, Hamid A, Friedman TC, Nguyen K, Tseng A, Marquez P, et al. Stress-induced analgesia and endogenous opioid peptides: The importance of stress duration. Eur J Pharmacol. 2011;650(2-3):563-7.

33. Chowen BJ, Fraser HM, Vician L, Damassa DA, Steiner RA. Testosterone regulation of proopiomelanocortin messenger ribonucleic acid in the arcuate nucleus of the male rat. Endocrinology. 1989;124(4):1697-702.

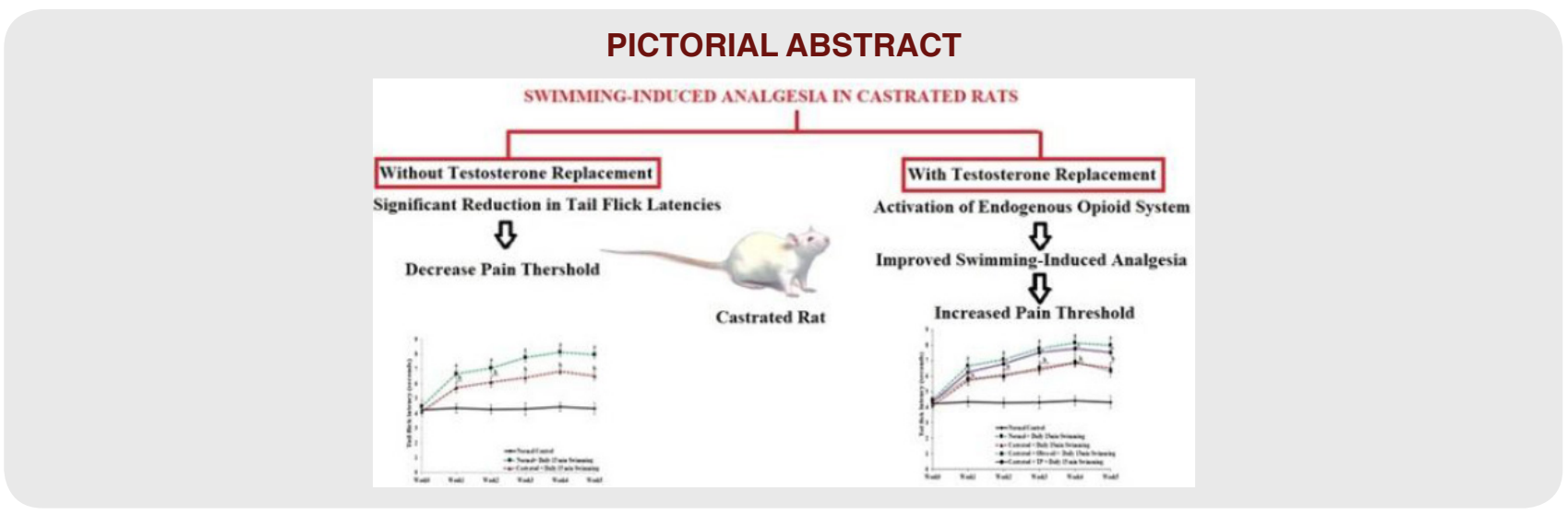




\section{SUMMARY}

- Pain is an unpleasant sensory and emotional experience associated with actual or potential tissue damage.

- Exercise elevates the pain threshold by triggering the release of endogenous opioids, which activate nociceptive inhibitory mechanisms.

- It has been observed that testosterone may increase the sensitivity of adult male rats to $\mu$ and $\mathrm{k}$ opioid anti-nociception.

- Naloxone (a well-known opioid receptor antagonist) significantly attenuates swim-induced anti-nociceptive effects in adult rats.

- In our study, regular swimming sessions might have proved to be beneficial in order to increase the pain threshold. Castrated male rats were found significantly less benefited by swimming sessions

when compared to intact male rats in terms of increase in pain threshold.

- Treatment with testosterone propionate $500 \mu \mathrm{g} / \mathrm{kg} /$ day s.c. was proved to be significantly effective in order to improve swimming exerciseinduced an increase in pain threshold in castrated male rats.

- The positive influence of testosterone on pain threshold might be mediated through its probable effect on the endogenous opioid analgesic system, which is confirmed by the intraperitoneal administration of naloxone. Concisely, the deficiency of testosterone could adversely affect regular swimming exercise-induced increase in pain threshold of an individual. Although, testosterone therapy can compensate for it.

\section{About Authors}
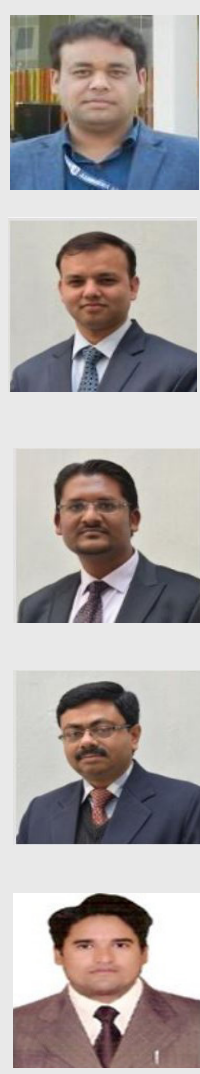

Mr. Dheeraj Kumar Sharma is currently Assistant Professor in SGT College of Pharmacy, SGT University, Gurugram, Haryana, India.

Mr. Niraj Kumar Singh is currently Assistant Professor in Institute of Pharmaceutical Research, GLA University, Mathura, has been actively engaged in Pharmacology and Toxicology research and teaching.

Mr. Ahsas Goyal is currently Assistant Professor in Institute of Pharmaceutical Research, GLA University, Mathura, has been actively engaged in Pharmacology and Toxicology research and teaching for last 5 years. He has been resourceful contributor of research papers in journals of national and international repute.

Dr. Jeetendra Kumar Gupta is currently Assistant Professor in Institute of Pharmaceutical Research, GLA University, Mathura, has been actively engaged in Pharmacology and Toxicology research and teaching for last 10 years.

Dr. Harlokesh Narayan Yadav is currently Assistant Professor in All India Institute of Medical Sciences (AIIMS), New Delhi, has been actively engaged in cardiovascular research and teaching for the last 10 years. He has been resourceful contributor of 20 research papers in journals of national and international repute. He was facilitated by various prestigious awards like Gold medal for Dr. Manjeet Singh Award (2010) for best research work in Molecular Pharmacology. Gold medal for N.N. Datta Prize (2010) for best published research paper in Indian Journal of Pharmacology (2009-2010), by Indian Pharmacological society.

Cite this article: Sharma DK, Singh NK, Goyal A, Gupta JK, Yadav HN. Role of Testosterone in Swimming ExerciseInduced Analgesia in Rats. Indian J of Pharmaceutical Education and Research. 2019;53(4):675-81. 